\title{
Tracing an outline of legal complexity
}

\section{ThOMAs E. WeBB, LANCASTER UNIVERSITY LAW SCHOOL ${ }^{*}$}

Abstract Autopoiesis and systems theory are terms often treated as synonymous by lawyers. This sleight-of-phrase elides the space between autopoiesis and systems theory, removing its content. Within this eliminated space there exist numerous understandings of systems approaches in law; one such understanding is complexity theory. Complexity entails a very different systems view of law to that of autopoiesis. In this paper I explore the concepts of complexity and their relevance to law. In tracing an outline of complexity, a number of contradictions, paradoxes, and additional questions are exposed which require further detailed analysis in the future.

\section{INTRODUCTION}

When lawyers talk about systems theory it is often assumed that they are talking about autopoiesis. This is because advocates of that theory treat autopoiesis and systems theory as synonymous terms when they are not. Legal autopoiesis is actually part of a wider set of ideas which can be grouped under the category of systems theory thinking. By taking ownership of the term systems theory, proponents of legal autopoiesis pre-emptively confine

\footnotetext{
* PhD Candidate, Lancaster University Law School, United Kingdom. The author is grateful for the comments and constructive criticism received from Drs Barbara Mauthe and Sara Fovargue of Lancaster University Law School. The paper has also benefited from the comments of those who attended the SLSA Annual Conference 2011, Systems, Complexity and Autopoiesis stream, University of Sussex, UK.
} 
lawyers' ideas about what a theory of systems could be about, and what view of the law a theory of systems should take. This imposed bias excludes natural challengers to the autopoietic hegemony. Complex systems theory is an umbrella concept which covers an array of alternative approaches to autopoietic systems thinking. The purpose of this paper is to trace an outline of a complexity theory perspective on law, with a view to positioning complexity theory as an alternative to the autopoietic hegemony. The literature on complex systems often amalgamates multiple elements of the range of these approaches and does not clearly acknowledge their origins within, or respective differences to, other similar systems approaches. Notwithstanding this, I argue that complexity theory, and specifically the form of what I call legal complexity and outline here, offers a novel and different systems perspective on how lawyers might view law in society. This novelty and difference is both in terms of offering a new conception of systems theory for law, and a different way of thinking about law in society.

I draw on the work of Cilliers (Cilleirs 1998, 2000; Richardson, Cilliers and Lissack 2001; Cilliers, Highlighen, Gershenson 2007) in my formulation of legal complexity. His position recognises that knowledge is contingent, local, and limited, and that consequently it is impossible to offer any view as the singularly correct perspective (1998, viii, 113-114, 116$117 ; 2001,11)$. Cilliers' model of complexity is one of an interactive learning, remembering system (1998, 90 and 99), capable of selectively forgetting redundant information to make space for newer, more pertinent, knowledge $(1998,92)$. The interacting parts of this construction suffer from their own locality, as well as their limited knowledge capacity and contestable perspective. Additionally, all knowledge is distributed unevenly across the system, making it impossible for any one individual to access all the system's information $(1998,95)$. These postmodern ideas, particularly those relating to alternative perspectives on reality which Cilliers contributes to the complexity debate, take my formulation of legal 
complexity in a different direction to that of others previously offered (for example Ruhl 1996a, 1996b, 1997, 2008; Ruhl and Ruhl 1997; Ruhl and Salzman 2002, 2003; Webb 2005; and Murray 2006, 2008 discussed below), but I deploy a different framework; one more suitable to law (for Cilliers method of deployment see 1998, chapters 2-5). In addition to these specific aspects of complex systems theory, Cilliers' more general ideas relating to the central features of complexity theory are also used, for example self-organisation, adaptivity and anti-reductionism $(1998,4-5)$. In complex systems, order emerges out of the quality of the interactions between parts, rather than the character of the parts themselves. This contrasts with reductionism which is the methodological belief that an understanding of the whole can be gleaned from a summing of the results of an examination of the individual parts observed in isolation (1998, 1-2; 2007, 118-119).

In order to support the claim that complexity theory offers a new perspective on law, I first comment on the systems approaches from which it can be distinguished; chaos theory and autopoiesis. Both of these systems approaches have been deployed in law and bear similarities to complexity theory, and thus it is important to consider complexity theory's treatment of them as well as clarifying their differences to it. I then give an overview of complexity theory and discuss the approach's appearance in law to date. Although I contend that complexity theory offers a different systems view of society which is capable of challenging the autopoietic hegemony, I do not directly compare the two here. Instead I give an introduction to complexity theory as it relates to law. This theory is of interest in its own right and should not be seen only in relative terms to autopoiesis; nevertheless, as autopoiesis is the dominant theory of systems in law some acknowledgement of it is appropriate. However, this does not mean that one should set out arguments for examining complexity theory further in the shadow of autopoiesis. The purpose of this paper is to position complexity theory as an interesting approach for law in its own right. The process of tracing 
an outline is a contingent one. The initial drawing together of the disparate ideas of complexity, as well as being only a general account, highlights a number of contradictions, paradoxes, and questions which will require further attention in future discussion.

\section{Alternative Systems APPROACHES TO COMPLEXITY THEORY}

Chaos theory is a theory of the natural sciences which has since spread to other disciplines and is a forerunner to complexity theory (Murray 2008, 238). Chaos theory is most naturally discussed as a mathematical theory and when deployed in this sense it refers to deterministic chaos; which is the consequence of nonlinear mathematical equations which produce bounded unpredictability. Nonlinear equations do not produce a single solution but yield a range of answers (Lorenz 1993, 14-15), and when plotted graphically the results show an intricate pattern which never repeats itself and also never strays outside of the possible range of answers (Ruhl 1996b, 862). This plot represents the strange attractor, also known as the butterfly attractor, which shows that while the results appear random they will not stray outside certain limits; their disorder is not structureless (Lorenz 1993, 14-15). Chaos theory as conceived of in law has carried over these central ideas, even when the mathematics was left behind (see for example Hayes 1992; Geu 1994). This means that chaos theory tends to examine narrow systems of a relatively small number of nonlinearly interacting parts, whereas complexity theory examines large systems consisting of a great many interacting components (Cilliers 1998, ix). Furthermore, chaotic systems self-organise largely based on the consequences of their mathematics, but complex systems do so on the basis of emergent behaviour generated out of interactions. So while both are feature unpredictability, this is for different reasons. 
Chaos theory's place in the popular consciousness (Lorenz 1993, 181-184; Cilliers 1998, ix) has made it possible for its ideas to infiltrate theories which appear similar or related in nature, such as complexity, creating the potential for misunderstanding. This situation is not helped by the fact that the same (though not in the sense of equivalent meaning) terminology is used to describe a different view of the world in the respective theories (Lorenz 1993, 3-5). These differences are often minimised, unacknowledged, or lost altogether when the ideas are transposed across disciplines (Cilliers 2000, 26), and this may explain why chaos and complexity theories, which are separate theories, are often conflated. To add further confusion, while chaos theory is a distinct theory of systems it is connected to complexity theory in that it was a forerunner to it, and consequently aspects of the theory have found "extremely limited" (Cilliers 1998, ix) application in the later approach. Attractors are an example of a chaos theory device which has been adopted by complexity theory (see infra pages 23-24). However, alternative understandings of the familial relationship between chaos and complexity theories have led to the former being treated as a narrow sub-category of the latter (Castellani et al. 2009, 119). Nevertheless, some of the literature recognises a difference between chaos and complexity theories, even if this acknowledgement is sometimes only implied (Cilliers 1998, ix and 98). Furthermore, the relationship between chaos and complexity is nuanced making the precise classification of, and demarcation between, each dependent on the context in which they are employed. Regardless of the similarities between chaos and complexity theories, I suggest that chaos theory is unable to offer a sufficiently detailed (and thus useful) systems theory explanation of law, given its tendency towards narrow examination of small-scale systems, with very few parts or participants. Conversely, complexity theory, supplemented by narrow aspects of chaos theory, is capable of offering a detailed understanding of large systems, such as the legal system, consisting of many participants. 
The theory of autopoiesis also has scientific roots. However, whereas chaotic systems are based on mathematics, autopoiesis was originally a biological theory (see for example Maturana et al. 1980). Autopoiesis is a theory concerned not with nonlinearity, as in chaos, but instead with understanding social complexity. Comprehensive introductions to autopoiesis have been provided by others (including King 2009; Mingers 1995; and Teubner 1988, 1993); here, I summarise the theory's essential elements. Autopoiesis views society as being made up of many functionally differentiated, operationally closed, cognitively open subsystems (law, politics, economics, health etc.). In autopoiesis law's function is to maintain "counterfactual [normative] expectations" (Luhmann 1992, 1426), it is supposed to provide answers (and expectations) about the legality or illegality of action (or prospective action), but it is not required to change when the facts (the event) does not meet with expectations (the legal requirements). The legal system performs a "consistency check" on the encountered facts against its expectations and determines the status of an action (Luhmann 1988b, 337; and 1989. 140) by applying its functional binary code of legal/illegal (King 1993, 223). As a consequence of closure, all communications not of a legal nature are outside of the system and so beyond the operations of it (King 1993, 223). Autopoiesis constructs everything internally; there are "no exchange relationships" with other systems (Luhmann 1988b, 337). Law can only imagine (by constructing an environment for itself) what another system might be thinking (King et al 1994, 263; and see Luhmann, 1988a). The closest a system comes to connecting with another system is through structural coupling, and even this mechanism only allows systems to connect indirectly and develop along parallel lines when they each have an interest in the same social event (King 1993, 225). Structural coupling is an entirely internal process within each system, with systems unable to see or access the coupling (Mingers 1995, 147). They only experience a channelling of information about events that it brings (Luhmann 1992, 1432). 
There has been interest in autopoiesis in some domains of legal scholarship, but this has been limited and, in reality, the pattern is "of wide indifference and locally intense engagement" (Thornhill 2010, 380). In contrast, other disciplines which have taken an interest in complexity theory, have subsumed autopoiesis under the heading of complexity theory, (Castellani et al. 2009, 171-179) limiting its application and giving it only "a very specific meaning." (Castellani et al. 2009, 127) Others, while positioning legal autopoiesis within a chaos/complexity discourse (Ruhl 1996b, note 10,857), paint it as being mistaken, (Ruhl 1996b, 904-906) and as a misunderstanding (Walby 2007, 457), “a sort of hybrid between complexity theory and legal formalism, [which] falls short of each in terms of explaining anything" (Ruhl 1996b, note 150 902). Autopoiesis projects an alternative ethos to complexity; their apparent similarities in terms of the tools used mask deeper differences in their outlook. It is, however, inappropriate to subsume autopoiesis under complexity (or vice versa) as each brings different ideas to bear on social phenomena. Consequently it is hard to state that either is better than the other and my purpose here is to demonstrate the alternative perspective offered by complexity theory.

\section{AN OVERVIEW OF COMPLEXITY THEORY}

Complexity theory, originating in physics and bio-chemistry in North America during the 1970s and 1980s (for history see Lewin 1992; Waldrop 1994) is a species of open systems theory. It has subsequently been developed in a number of disciplines beyond the natural sciences (for examples see Castellani and Hafferty, 2009; Cilliers, 1998, 2000; Geyer and Rihani. 2010; Mitleton-Kelly, 2003; Rescher, 1998; Sawyer, 2005; Walby 2007). Complexity's openness means that a system's internal organisation does not respond to one specific category of environmental stimuli, but is capable of selectively interacting with all in 
its environment. The system itself decides what information it will interact with and what meaning it will assign to it. A complex system is an adaptive, learning system; its understanding of the environment is changeable in the light of interactions and received information. Due to its capacity to learn, a complex system is capable of resisting change; it can make decisions as to whether to react to environmental stimuli. This decision could be based, but not necessarily, on whether it understands the information. Whilst a complex system is open this does not mean that everything affects it equally, that the system is not in control to some extent, or that "anything goes" (Cilliers 1998, viii, emphasis added). Complex systems are constituted out of a large number of relatively homogenous parts acting in accordance with a set of rules. System parts interact under these rules and from this system behaviour and organisation emerges. Importantly, the form of system organisation and behaviour cannot be predicted by examining the constituent parts, and the particular development of the system cannot be predicted from an observation of its starting point. Finally, the homogenous interacting parts of complex systems, in the case of human social systems, are people. However, as discussed below, all knowledge and information within the environment is, as well as being distributed unevenly across the environment (Cilliers 1998, 95), contingent, contestable, and incomplete (Richardson et al. 2001, 10-11).

These characteristic traits of complex systems emerge out of a number of features and devices. However, as legal autopoiesis confines debate about systems theory in law it is important that any given understanding of legal complexity does not do the same. The features and devices discussed here thus represent the outline of one position, in truth "there are an infinite number of ways to talk about complexity" (Richardson et al. 2001, 11). Ruhl, for example, offers an alternative characterisation of legal complexity which is discussed below (Ruhl 2008). Moreover, attempts to demarcate correct or incorrect classifications of complexity are, as will become clear, "contradictory to the fundamental complexity message" 
(Richardson et al. 2001, 12). It is therefore relatively easy to justify an abandonment of elements of complexity theory used in other disciplines, including the mathematical rigour, the preference for computer modelling, and the reliance on data sets, as inappropriate for a general theory of legal complexity (however see Castellani et al. 2009, 121). Legal theory has tended not to rely on such practices preferring a philosophical method of constructing theories based on the opinions and observations of a given writer, and therefore the application of complexity theory to law need not draw on the methods of other disciplines; this is demonstrated by the deployment of complexity in law so far.

\section{COMPLEXITY THEORY'S APPEARANCE IN LAW}

The most well-developed vision of law and complexity has been offered by Ruhl (1996a, 1996b, 1997, 2008; Ruhl and Ruhl 1997; Ruhl and Salzman 2002, 2003), and his work has contributed to the appearance of complexity theory and law in the UK (see Murray 2008, 238-242). ${ }^{1}$ Much of Ruhl's work draws on the chaos theory and law literature (see his various references to Geu 1994), and on chaos theory literature more generally. This is evident in his 'science of surprises' (first deployed in 1996a, 1438) which is based around ideas of chaos, emergence and catastrophe. Ruhl also makes use of attractors, transferring the idea directly from chaos theory into complexity (first deployed in 1996a, 1440-42; see also 1996b, 863-865); indeed, his references to weather patterns and dripping taps suggests a relationship to the fractal geometry of chaos theory which is absent in complexity (1997, 936). However, there are also references to "irreversibility" (Ruhl and Ruhl 1997, 409-410) and "feedback" (Ruhl and Salzman 2003, 808); concepts which can be found in either chaos

\footnotetext{
${ }^{1}$ There are other small bodies of work on law and complexity (for example Georgia State University Law Review, 2008) but, in general, the adoption of complexity theory within law has been limited.
} 
or complexity theory. Also present are the more familiar complexity notions of limited local knowledge of individual actors (1996a, 1450-1451) and a clear rejection of reductionism (1996b, 853). Ruhl departs from pure mathematical chaos theory given the references to 'complex adaptive systems' distributed throughout his work, and the content of his latest exposition of these ideas $(2008,896-901.904,906)$. In essence Ruhl's work is situated in complexity but its foundations appear to have been constructed in chaos and law. This is most likely due to the absence of any available literature on law and complexity prior to Ruhl's work.

Ruhl implies that humans can overcome their limited knowledge to shape some aspects of the legal system through their intervention in the rule- (law-) creating process (1996b, 885-886). He does not go so far as to say that humans can control complex systems but an awareness of how complex systems function, particularly an awareness of which attractors they are currently built around, can aid the law-making process to possibly avoid some potential pitfalls generated out of the unknown variables of the system, and the inherent unpredictability of the consequences of system interactions (1996b, 926-928). Ruhl's more recent focus is on regulatory efforts in environmental law and he uses complexity theory as a means to explain regulatory failings and routes to potentially more effective regulation (Ruhl 1997; Ruhl and Ruhl 1997; Ruhl and Salzman 2002, 2003). More generally, he sees complexity as offering a theory capable of explaining the processes of legal development and stagnation (Ruhl 1996a, 1996b, 2008).

Following and drawing upon Ruhl, Murray constructs a novel vision of complexity theory which primarily utilises Deleuze and Guattari's work on chaos and complexity theories (Murray 2006, 2010). In this respect, Murray bases his understanding of chaos theory on different premises. Rather than focusing on the general idea of complexity as Ruhl does, Murray is more concerned with the processes by which complex organisations emerge 
and are maintained. The product of this is termed emergent law and seeks to explain how the state may have originally appeared $(2006,150)$. Emergent law is concerned with the selforganising emergence of systems from chaos, taking place "in open and dynamic material dissipative systems" $(2006,132)$, this is the process by which complex systems emerge. Instead of models and boundaries, the system is described by "abstract machines" which "define the patterns and thresholds" of, and "diagram and arrange," the system $(2006,132$ 133). Through these abstract "machinic processes" complex systems are able "to learn, evolve, and under-go metamorphosis as they seek to maintain a dissipative structure as their environment changes" $(2008,236)$. However, instead of "systems" the theory is based around DeLanda's “assemblages" (DeLanda, 2006), where the "virtual activities of the abstract machines are developed in intensive complexity" (2006, 132-133). Within these virtual spaces abstract machines build imaginary realities of the environment which find their way to "the actual" $(2006,133)$. This provides a useful explanatory link of how complex systems' models of reality find their way from the imagined model to the actual reality (2006, 138). The same can be said of the additional device of "the refrain" which allows "a brain to abstract itself from the here and now and think in terms of a dynamic consistency between a number of heterogeneous matters of expression" $(2006,138)$. Assemblages lay down territory as they self-organise; they self-organise their own territorial limits $(2006,142)$. However, they simultaneously lose other territory as the environment shifts around them; this is the process of territorialisation and deterritorialisation (2006, 133-134).

Murray's alternative construction of complexity still contains certain recurring features of complexity such as emergentism, as noted above, and anti-reductionism. Murray's anti-reductionism manifests as a fairly withering and sustained attack on autopoiesis, with complexity portrayed as a "significant advance" $(2008,228)$ on autopoiesis" position. Autopoiesis is suggested to have incorrectly narrowed and limited the complexity 
of the social world, whereas complexity offers "a much broader theorisation" $(2008,234)$. Demonstrating further acceptance of emergentism and the principle of irreversibility, Murray's formulation of emergent law seeks out different understandings of law in the form of "lost, hidden, local, bottom-up, emergent modes of legality" (2008, 243-245), seeing them as being part of "an irreversible historical trajectory that is pushed, pulled, and reshaped by a large number of competing and changing socio-legal attractors" $(2008,240)$. Law is a contested space, not all of which is visible to the actors present in the legal system. It is a dynamic system constantly being changed by both its own processes and the processes of forces beyond it. Murray criticises autopoiesis' operational coding for eliminating or at least suppressing the dynamic quality of complex systems, placing the system closer and closer to equilibrium which for a complex system would mean entropy (death) (2008, 234-235). Murray's examination of law's complexity appears more as an exercise to understand the processes which caused law to emerge and get to this point. This indirectly offers an explanation for how law continues to change, but Murray does not offer examples of how his emergent law relates to any concrete circumstances in the way that Ruhl connects his construction to environmental regulation.

Webb combines Cilliers' postmodern account of complexity with autopoietic undertones to produce his vision of complexity and law. However, the systems-image created is not an autopoietic one in the "conventional" sense $(2005,240)$; nevertheless, his model comes closer to adopting notions from the more developed theory of autopoiesis into the fledgling theory of complexity and law. Indeed, Webb understands autopoiesis as a "significant branch of complexity theory" (2005, 227 at note 3$)$, but he appears to treat the ideas of Luhmann and Teubner as separate to those of Cilliers (Webb 2005, 229-231; but see autopoietic influence 231-234). It also needs to be noted that Webb's use of Cilliers, given the lean towards autopoiesis, entails a different deployment to the reading of Cilliers traced in 
this paper. However, neither the (possible) autopoietic inspiration nor the different deployment of theoretical structures is reason to set aside the product. As Webb writes, there is an "absence of a unifying theory..." leading to "a lack of common language and some significant local differences of approach" in complexity thinking $(2005,232)$. There is no lexicon of complexity (Richardson et al. 2001, 11), and the very nature of complexity theory expects a differentiated approach across reality.

Webb ascribes to complexity the tenets of unpredictable emergent order and irreversibility $(2005,229)$, and also follows Cilliers on the limitations of the localised, contingent perspectives of any given observer, and the existence of memory and learning in systems (2005, 231 and 235). Again, the system is built out of many interactions $(2005,232)$ but, and this is the most obvious entry of autopoiesis into this conception of law and complexity, the maintenance of boundaries seems to be conducted internally by the system which seeks to maintain itself independently from the environment $(2005,233)$. However, the gift of complexity, which is perhaps not to be found in autopoietic conceptions is that it gives "an insight into the local, the unplanned and unintended, the order that emerges at the edge of chaos" $(2005,231)$. Complexity, in Webb's understanding, offers a framework for explaining the unpredictable and emergent occurrences of the legal system. In treating autopoiesis as an aspect of complexity, rather than as an alien theory, Webb is able to draw on the foundational ideas of that method, while integrating the broader complexity principles offered by Cilliers. This changes entirely the consequences of his autopoietic inferences. Although he draws on autopoietic coding and the idea of the functional differentiation of society $(2005,233)$ he projects a system image of something like autopoiesis but not as we know it. The addition of a memory and learning capacity in a complexity sense, rather than the traditional legal autopoiesis understanding, represents an attempt to overcome some of the perceived shortcomings of autopoiesis without wholly subsuming it under complexity. 
Perhaps the most important distinction to make between autopoiesis and Webb's approach to law and complexity is the re-appearance of the individual. Significantly, the individual is empowered or at least imbued with a responsibility for their actions. While all knowledge is local and limited, the unpredictability of interactions which people have with one another means that they could have a very large impact on reality; because there is a nonlinear relationship between cause and effect. While the individual actor could be portrayed as a mere $\operatorname{cog}$ in the system, or indeed relegated to the level of psychic systems by autopoiesis, here complexity accords the individual the opportunity for impact. In line with the idea that systems theory does not promote any particular value system, Webb suggests that values in complex systems are neither transcendent or immanent but instead emergent $(2005,239)$. The system does not treat the empowerment of the individual as either a "good" or "bad" thing, but rather as simply an emergent consequence of system processes. Values in the system emerge from the interactions of the components of the system and continue to exist so long as they aid the perpetuation of that system $(2005,239)$. Democracy, or something like it, is likely to continue because of the way it enables interaction among the component parts of the system in a way which is richer and less constrained than in any dictatorial environment. Ultimately it should be remembered that the values themselves are contingent and their meaning open to contestation, so the perpetuation of these ideas broadly speaking may not be entirely desirable, depending on the persuasions of the system.

Webb's contribution to the debate about systems theory thinking in law is certainly the idea that aspects of different systems theories can be combined. This changes the character of those theories, but this is not necessarily a flaw. Generally problems with autopoietic systems accounts seem to be concerned with its elimination of the individual (Bankowski 1996), or issues surrounding its particular method of dividing and running society (see King 2001 for a summary of critical efforts). It does not seem to be an issue of 
the idea of systemic organisation which is a problem for lawyers, but the particular method offered by autopoiesis. Thus, if it is possible to construct alternative systems based formulations which take account of these concerns, which Webb demonstrates complexity has the potential to do, a systems view may have success. I thus now outline another version of complexity theory to those set out above; a version which is designed to offer a viable alternative systems approach to autopoiesis.

\section{An Alternative Formulation OF Legal Complexity}

It is important to recognise that any classification of the features and devices of complexity is "provisional and definitely local” (Ricardson et al. 2001, 12). Complexity theory “...is a set of theoretical and conceptual tools; not a single theory to be adopted holistically" (Walby 2007, 456). To avoid confusion arising as a consequence of the selection of particular tools, theorists should be explicit about which elements of complexity are being adopted, how they are received, and what informs that choice. To that end, a brief summary of the features and devices of legal complexity as outlined here is given below; self-organisation and emergence, internal models, path-dependency and evolution, contingency, contestability and locality, and attractors. These features and devices are grouped together as they relate to the inside (the system), the boundary (between system and environment), the outside (the environment) and the whole (relating to processes linking inside, boundary and outside).

\section{INSIDE THE SYSTEM}

A complex system is a self-organising system wherein organisation is seen to spontaneously emerge from disordered chaos (Cilliers et al 2007, 126; Waldrop 1994, 124). 
The system must orientate itself towards the environment with incomplete information, and an awareness that the knowledge it does possess is both local and contingent (Richardson et al. 2001, 10-11). To the imaginary outside observer, as to the system, the order which appears from disorder cannot be predicted from a reductionist examination of the system components. The observer is called imaginary because of the impossibility of an observer concurrently holding two contradictorily contingent perspectives. That is the impossibility of an observer achieving a vantage point beyond the system whilst simultaneously viewing the system from the system's own perspective). Self-organisation is an emergent quality of complex systems entailing a transcendence of their constituent ingredients (Urry 2003, 13; for discussion of emergence see Goldstein, 2000; and Holland, 1998). Thus, order emerges from the nature of the interactions of the parts of the system and not of the parts themselves (Mitleton-Kelly 2003, 40). As such, organisation is the product of many local decisions; there is no central hub which controls the organisation of the system. Control is distributed throughout the interacting parts (Cilliers 1998, 12).

Although the system obeys certain simple environmental rules, (particularly the physical limitations on a system, as well as the linguistic limitations of the interactors) which constrain the interactions of the component parts (Geyer et al. 2010, 6; Ruhl 2008, 892), the accessibility (knowability) and utility of these rules, as well as their apparent simplicity, are questionable in human complex systems. Any list of these simple rules is probably "nonfinite" (Ruhl 1996b, 854). It is perhaps most appropriate to consider these rules as existing hypothetically, but as also not being capable of specification. The result of any attempt to note down the rules would be legitimately contestable. Nonetheless, acknowledging the presence of constraining rules, the form the system takes is not predictable; the whole is greater than the sum of its parts (Geyer, et al. 2010, 15). What can be said in a general sense is that micro-level interactions produce meta-level regularities (see 
Sawyer 2005, 3; Ruhl 2008, 898; Cilliers 1998, 92). It is the interaction of the system components within the constraints of their reality which causes self-organised behaviours to emerge. It is important to stipulate that although the micro- and meta-levels exist simultaneously, they do not appear reducible; they cannot be isolated from one another.

The legal system can be understood as a complex self-organising system. The character of the legal system cannot be discerned simply by learning every case and statute on the books, nor can the form into which it will develop at any point in the future be predicted by such methods. One must understand the context of law inasmuch as that possible. Even if one could know the context of every case and statute, which one cannot (Rescher 1998, xiv-xv), knowledge of the legal system would still be limited by one's local context, interplaying with the respective contexts which one may be trying to address. In this way it is never possible for any given participant in the system to be aware of even a fraction of the total complexity of the system (J. Webb 2005, 235; and see Cilliers 1998, 95). Acting on incomplete, contingent, local knowledge, participants interact with the mechanisms and models of understanding of the legal system (such as the courts and administrative agencies) (see infra 9-12), which generate decisions, and with one another, changing the organisation of the system. Collections of local interactions lead to the development of emergent meta-level principles of the legal system, such as human rights. However, the legal system also demonstrates how the micro- and meta-levels are inseparable as interpretations of the metalevel are contested at the micro-level. The controversy over the existence, scope, and meaning of the right to life (and death) and the meaning of inhumane and degrading treatment are prime examples of this.

As a consequence of the inaccessibility of total reality, even the development of relatively confined aspects of the legal system cannot be predicted. It is not possible to say how many individuals' models of understanding will interact and develop. While a solicitor 
giving generalised legal advice to a client may be able to predict the outcome of simple cases, such as traffic offences which often appear as a question of fact rather than opinion (was the driver breaking the speed limit? Was the driver's blood-alcohol level above the legal limit?), it will be less possible to determine the sentence which will be passed in a given case due to various mitigating and other circumstances particular to it. Beyond this, it is certainly not possible to predict how hundreds of cases, even simple ones, heard over time will alter the justice system, public perceptions of law, legislative action, the prison population and so on. It is in turn not possible to predict how any other non-legal matters (such as the changing cultural attitudes towards alcohol consumption, the increasing effectiveness of automated vehicle safety technology, or improved surgical techniques for traumas sustained in traffic collisions) connected with these issues will impact on the development of the law, or the outcome in any given case. What is more, events which appear completely disconnected from others, indeed utterly irrelevant, may still have a legal impact. These need not even affect the decision makers directly; and could be less proximate than what a judge had for breakfast. Most importantly, it is not possible to see how each of these responses to the development of road traffic law will reflect back on its development. This may seem an obvious proposition but complexity offers an explanation for why this is the case.

The unpredictability of legal development is due to both the emergent nature of such development coupled with the idea that there need not be a connection between the occurrence or size of any cause (though it might only appear as a cause in hindsight) and the resultant effect; the relationship between cause and effect is nonlinear (Waldrop 1994, 142). Furthermore, any decision of the system, borne out of its local interactions, may be based on seemingly irrelevant considerations. The information of relevance to the model is not unchanging but dynamic and interfaced with considerations which are not obviously legal. A case which is the correct view of the law today may not be so tomorrow and the model must 
therefore be adaptive. Perspectives as to the correct or incorrect view remain contestable. A court judgment as to the correct position denotes the meta-level regularities as perceived by the judge, and argued by the advocates, at that time. This can, of course, be contested by other judges, advocates, clients, academics, legislators, officials, journalists; indeed, anyone. These divergent understandings of the meta-level regularities represent the contestation of the meta-level at the micro-level, in turn generating newly adapted regularities. It is through the contestation of meta-level regularities at the micro-level that the system self-organises its internal composition out of a disordered chaos of interactions. Information that builds the meta-level organisational regularities of the system is incomplete and contestable. Meta and micro are constantly contested causing the system to re-self-organise in the light of changing circumstances. In this way the system learns and adapts to change in an attempt to secure its survivability.

\section{THE BOUNDARY OF THE SYSTEM}

The way in which a system, open or closed, possesses a boundary is complicated and merits deeper investigation beyond the remit of this paper. Thus, my discussion is only a tracing of the concept. In one sense there exists the actual system boundary, inasmuch as boundaries can be said to exist at all on a complexity view of the world (Richardson et al. 2001, 9). Indeed, it might be more appropriate to view the world as one complex system and any demarcation of it as merely a "partial complex system" missing out some of reality (Richardson et al. 2001, 9). Beyond this, there are at least two meanings of "boundary" in complexity's understanding. First, the boundary of what we might more commonly identify as a (partial) "system," like the legal system. The boundary in this understanding, if it exists, is objectively unobservable due to the contingent nature of complex systems. The second 
meaning is the observed boundary of the (partial) system. In drawing the boundary from a perspective limited by context, the observer eliminates some of the complexity of the reality under observation. This understanding brings into sharp relief the contingency of boundaries. Often, for the purposes of analysis, an observer will deliberately draw a boundary, knowingly omitting some part of the (partial) system reality under observation (Richardson 2004a, 77). The following explanation primarily focuses on these two understandings of boundary.

Complex systems are open systems and, as such, their boundaries "are not clearly defined" (Cilliers 2000, 25). Not only are they not permanent or knowable to the individual, but their contestable nature within the system renders them transient (Richardson et al. 2001, 9). However, the system does not randomly (i.e. in a non-deterministic chaotic sense) alter its organisation or boundaries in response to all stimuli, nor does it respond equally to all effective stimuli. The system produces models of reality which "allow [it] to anticipate the world," and respond (Waldrop 1994, 177; see original idea in Holland 1995, 31-34). Such models provide an individual, at the micro-level, or a system, at the meta-level, with a means of making sense of environmental information, to decide whether information is pertinent, and thus whether it should be classified as "legal" (in the case of the legal system). This allows the system to then adapt both its organisational rules and structure in the light of such decisions on information. The system is therefore defined, at the boundary, by what is considered legal, even though the meaning of "legal" is unfixed and indeterminate. The boundary is contingent and remains unclear. Complex systems are capable of such reconfigurations because they possess both a learning capacity and a memory (Cilliers 1998, 90 and 99). The boundary of the system is therefore flexible and capable of changing according to the regularities which emerge at the meta-level of the system.

A complex system's memory is not infinite; internal and external resources are limited (J. Webb 2005, 236) thus, the memory of legal complexity is contained within the 
participants in the legal system. While information might be recorded in casebooks and journals, individuals must have access to that information for it to count for anything and contribute to boundary making. The mere existence of some legal communication is not sufficient. To cope with the limits of its memory the system perpetually undergoes a process of "selective forgetting"; that which "is not used simply fades away" freeing up space (Cilliers 1998, 92) and this alters the boundary. Conversely, that which is used often is harder to forget (Cilliers 1998, 92). For the legal system, one model for understanding reality could be represented by the body of precedents and legislation which have accumulated over the system's history; some of these cases and statutes have been forgotten as others have appeared and achieved seminal status (J. Webb 2005, 235). The meaning of this body of information is contestable.

The (in)accessibility of information is a consequence of information's localised nature. Just as information within the environment is localised, and so may not be accessible to the system, the same is true of the information stored within models of understanding. All information is stored in a "distributed fashion," (J. Webb 2005, 235; and see Cilliers 1998, 95) so different knowledge exists in different parts of the system. Though all this information might be characterised as legal, it will not always contribute to boundary construction. Partly because of the way knowledge about the models is stored (in individuals) and partly because of the inherent contingency of that knowledge (and the contingent, subjective nature of meaning-making) (J. Webb 2005, note 19, 231), the understandings provided by the models are themselves contestable (Cilliers 1998, 122). Broad propositions (meta-regularities) are predominantly accepted as true, such as "legislation is law" and "case law is law", whereas more specific meta-level conclusions may not be. For example, a case may not be cited either because it (the meta-level regularity) is locally inaccessible or because it is interpreted as not enhancing the argument of the particular advocate at a particular time or place. 
Essentially, meta-level regularities can be localised and suffer from their localism by not contributing to a particular boundary construction. Similarly, arguments between advocates, and the conflicting opinions of judges, demonstrate that the meaning of cases and statutes is contestable. Incidentally, this is an example of the simultaneous formation and contestation of meta-level regularities at the micro- and meta-levels respectively. This is an ongoing argument about what the law means and thus what is and is not within the legal system.

The sheer volume of literature currently available on any given subject renders "comprehensive knowledge effectively unattainable" (Rescher 1998, xiv-xv) we are all perpetually "in "the shadow of the whole" (Richardson 2004a, 77). So while a capacity to learn allows the legal system to change, its limited memory (the memory of system participants manifested in their models), the locality and contingency of knowledge, and the innate imperfections of its models (themselves contingent and local whether they are at the micro- or meta- level) makes perfect prediction of the consequences of information (and action taken on the basis of information) impossible, even discounting the problems posed by nonlinearity. This opens up the possibility of the system making mistakes in the sense that system stability is affected, and not in the normative sense of being morally "wrong" choices (on values in complex systems see J. Webb 2002, 2005; see also infra 12-15). As such, complexity theory generally, and the internal models of complex systems specifically, cannot describe the totality of the complexity, i.e. reality, of the system or its environment (Cilliers 2000, 28), rendering even (potentially) partial boundaries contestable.

\section{BEYOND THE SYSTEM: THE EXTERNAL}

Theories of systems view the world as being comprised of a variety of systems occupying an environment. Due to their somewhat open nature, a differentiation between 
system and environment is difficult in complex systems. However there are, beyond the system, phenomena which contribute to the overall structure of the complex environment. We might call these environmental meta-regularities. In the case of legal complexity these can be more succinctly termed attractors. Attractors are a familiar concept in chaos theory and come in three 'flavours': fixed-point, limit-cycle and strange (Ruhl 1996b, 863-864). In the context of complexity theory, as presented here, the term attractor is used to describe a point of attraction towards which systems flow. Although attractors themselves do not exert a "gravitational force" per se (Ruhl 1996a, note 137 1440), they do "deform the possibility space [of reality]...from above" (Goldstein 2000, 16).

Whether an attractor exists is contestable and they are best employed as a descriptive device to explain why particular social influences and structures (characterised as attractors) are dominant over others in some societies (i.e. democracy over feudalism, capitalism over communism, and the rule of law over arbitrary dictatorship). In this way, attractors are a dynamic representation of the changing environment (Ruhl and Salzman 2003; Urry 2003, 138-139). They can be characterised as representational of the forces leading to meta-level regularities of the environment, as opposed to regularities in the system. Where certain values are ascendant, like those noted above, with long lineages, some explanation for this stability is offered by attractors. The analysis offered by any explanation (observation) utilising attractors can only be one contestable analysis, with others probably possible. This is because any observation will view the purpose and capacity of attractors differently. Differing observations may choose to ignore certain attractors, making the outcome different.

Due to their nature as descriptive tools, attractors "represent the behaviors that flow from forces of order and disorder that might exist within a system..." (Ruhl 1996a, 1440 emphasis added). In the understanding of the observer attractors can be used to characterise particular forces acting upon a system, (Ruhl and Ruhl 1997, 423-424) but this is contestable. 
Attractors are best used as a descriptive device around which to build an explanation for why certain developments occur over time. What is characterised as an attractor is a decision for the observer. Therefore, the existence and location of attractors is contestable. This decision will also be influenced by the line the observer chooses to draw as regards the boundary of the system.

\section{WHOLE-SYSTEM/ENVIRONMENT PROCESSES}

Complex systems are adaptive. They have a capacity to learn and remember which manifests internally in the form of self-organisation, at the boundary as models which help a system to understand its environment and respond to stimuli, and in the environment which also changes in response to the interplay of its component parts. Complex systems evolve with reference to their environment (Kauffmann 1993). The system, acting under "internal and external forces" (Lewin 1992, 149), reacts to changes in its environment by continuously re-self-organising in the light of feedback on its interactions from the environment (information) (Waldrop 1994, 179). All systems co-evolve with one another and the environment making it difficult to deliberately cause and predict the consequences of environmental change (Ruhl 2008, 903). Biologists term this kind of competitive, coevolving behaviour between systems the "Red Queen Phenomenon" (van Valen 1973; concept used in Ruhl and Salzman 2003, see particularly 784-785). Attempts by humanity to direct a complex social system are likely to be unsuccessful because the "space of possibilities is too vast" and humans possess "no practical way of finding the optimum" (Waldrop 1994, 147). The absence of centralised control and the distributed nature of knowledge, memory and action contribute to this, and the optimum is of a dynamic and also contingent quality. 
The internal conflicts of a system generated by the contingency and locality of knowledge are interactions which create higher level regularities. As each system participant implements their own contingent vision of adaptation to the environment this feeds upwards to create the higher- (eventually meta-) level regularities which are the system's behaviour as a whole. However, systems will not always adapt correctly (Ruhl 1996a, 1412); their emergent responses to environmental stimuli are based on imperfect contingent local knowledge. In order for the legal system to remain relevant its laws, and legal theories concerning those laws, must adapt to wider social change; however, the change that is made to a law or theory (a theory as a model) may prove a maladaptation. For example, a poorly adapted rule might appear irrelevant, overly rigid, too flexible, inaccurate, or disjointed, to those to whom the rule applies. Unsuccessful adaptation could result in inobservance or misapplication to overcome the perceived problem. This behaviour is liable to cause either a form of disorder through misapplication or non-observation, or stagnation whereby the rules are forgotten, neither being misapplied or acknowledged but going unobserved. However, a poorly adapted rule will continue to change because no part of a complex system is ever entirely static, though it might be extremely stable. Similarly a maladapted theory, which posits a model through which an individual or the system attempts to understand information, will result in the individual or system misunderstanding information, leading to misapplication and/or misinterpretation.

Complex evolution cannot be confused with traditional Darwinian ideas which equate evolution with an inexorable progress towards perfection. Perfection (the optimum), if it is possible to attain, is transient, and contingent; beauty being in the eyes of the beholder. Complex evolution is simply a change resulting from an environmental stimulus, it is not necessarily the correct development, and it is most definitely not progress. The idea that evolution involves progress and betterment misconstrues the concept (see Castellani et al. 
2009, 23; Cilliers et al. 2007, 120). System participants make choices all the time, closing off the road not taken (in autopoiesis see King 2006, 41), and systems can become locked onto a particular path of development, capable of making only incremental changes and requiring a massive environmental upset to trigger any significant alteration. By becoming locked onto a certain track of behaviour, elements of the system come to depend on it for their existence; this is path-dependency (on the difficulties of legal lock-in see Hathaway, 2001). In this way, complex systems adaptability can be constrained by their past choices. System history is an aspect of system context. However, due to nonlinearity it is possible for unexpected and significant changes to supersede the effects of path-dependency.

\section{CONCLUSION}

The reading offered here, drawing primarily on the work of Cilliers, shows recognisable links to the work of Ruhl, Webb and Murray. Indeed, the theories each share in the notion of anti-reductionism, adaptability, learning, memory, irreversibility, and emergent self-organisation. This suggests that whilst there may be varied tools in complexity theory thinking in law, there are certain characteristics which one would expect to find in any reading of legal complexity. The version of complexity offered here is not the only one available in law, and alternative versions have been noted. The varied scope of these different interpretations demonstrates that debate will continue as to what a theory of legal complexity should contain. In this way it is necessary to read this contribution in the light of the relatively contained wider debate on this question. It is also important to consider complexity theory's relationship to other systems theories in law to consider the criticisms which have been made and to actively distinguish complexity from them. 
As to the limited deployment of complexity in law so far, this most likely due to a lack of awareness as to its meaning and utility. It would therefore be inappropriate to dismiss it out of hand as incapable of challenging the established systems theory of autopoiesis. There are a number of parallels and similarities to be drawn between complexity and autopoiesis, and this suggests that some conceptual cross-pollination may be possible. In this way, Webb's article, which implicitly overlaps complexity and autopoiesis, may represent a first step (see particularly 2005, 229-234). It is likely that any such move would meet with opposition, not least because autopoiesis is often portrayed as the systems theory of law and social systems. However, while autopoiesis has often faced criticism from non-systems perspectives it has rarely been subject to a systems critique (however see Ruhl 1996b, 901906 and notes 146-156). Such a critique would be capable of offering a new perspective on autopoiesis.

I have sought to outline a perspective on the novel theory of legal complexity primarily as a means of raising awareness and encouraging engagement. As such, this piece is best characterised as a trace; both in the sense of outlining initial thoughts and in marking the contours of the present debate. Contradictions, paradoxes, and questions have emerged, both within this piece and elsewhere, which I have not sought to answer yet. It is almost certain that, in the further exploration of these ideas, there will be a need to alter the very general outline offered here. Certainly the construction presented is based on a contingent reading of Cilliers' perspective which could be contested. Complexity is a limited theory of explanation which recognises the boundaries of our explanatory capacity. For law it offers explanations about the difficulties of managing legal regulation and, more generally, the development of legal systems. 
LA1 4YN

United Kingdom

t.webb@lancaster.ac.uk 


\section{REFERENCES}

Bankowski, Zenon. 1996. How Does it Feel to Be on Your Own? The Person in The Sight of Autopoiesis. In Law as Communication. Ed. David Nelken. Aldershot: Dartmouth Publishing.

Castellani, Brian, and Frederic Hafferty. 2009. Sociology and Complexity Science: A New Field of Inquiry. Berlin Heidelberg: Springer-Verlag.

Cilliers, Paul. 1998. Complexity and Postmodernism: Understanding Complex Systems. Abingdon: Routledge.

---- Cilliers, Paul. 2000. What Can We Learn From a Theory of Complexity?. Emergence 2(1): 23-33.

Cilliers, Paul, Francis Heylighen, Carlos Gershenson. 2007. Philosophy and Complexity. In Complexity Science \& Society. Ed. Jan Bogg and Robert Geyer. Oxford: Radcliffe Publishing.

DeLanda, Manuel. 2006. A New Philosophy of Society: Assemblage Theory and Social Complexity. London: Continuum.

Colloquium on Law and Complexity. 2008. Georgia State University Law Review. 24(4).

Geu, Thomas Earl. 1994. The Tao of Jurisprudence: Chaos, Brain Science, Synchronicity, and the Law. Tennessee Law Review 61(Spring): 933-990.

Geyer, Robert and Samir Rihani. 2010. Complexity and Public Policy: A New Approach to Twenty-First Century Policy and Society. London: Routledge.

Goldstein, Jeffrey. 2000. Emergence: A Concept Amid A Thicket of Conceptual Snares. Emergence 2(1): 5-22 
Hathaway, Oona, A. 2001. Path Dependence in the Law: The Course and Pattern of Legal Change in a Common Law System. Iowa Law Review 86(Jan) 601-665.

Hayes, Andrew, W. 1992. An Introduction to Chaos and Law. University of MissouriKansas City Law Review 60: 751-773.

Holland, John, H. 1995. Hidden Order: How Adaptation Builds Complexity. Reading, Massachusetts: Helix Books.

---- Holland, John, H. 1998. Emergence: From Chaos to Order. Oxford: Oxford University Press

Kauffman, Stuart. 1993. The Origins of Order: Self-Organisation and Selection in Evolution. New York: Oxford University Press

King, Michael. 1993. The 'Truth' About Autopoiesis. Journal of Law and Society 20(2): $218-236$

---- King, Michael. 2001. The Construction and Demolition of the Luhmann Heresy. Law and Critique 12: 1-32

---- King, Michael. 2006. What's the Use of Luhmann's Theory? In Luhmann on Law and Politics, Critical Appraisals and Applications. Ed. Michael King and Chris Thornhill. Portland, Oregon: Hart Publishing.

---- King, Michael. 2009. Systems, Not People, Make Society Happen. United Kingdom, Holcombe Publishing (e-book).

King, Michael and Anton Schütz. 1994. The Ambitious Modesty of Niklas Luhmann. Journal of Law and Society 21(3): 261-287 
Lewin, Roger. 1992. Complexity: Life at the Edge of Chaos. Oxford: Macmillan Maxwell International.

Lorenz, Edward, N. 1993. The Essence of Chaos. Seattle: Washington University Press.

Luhmann, Niklas. 1988a. The Unity of the Legal System. In Autopoietic Law: A New Approach to Law and Society. Ed. Gunther Teubner. New York and Berlin: Walter de Gruyter Publishing.

---- Luhmann, Niklas. 1988b. Closure and Openness: On Reality in the World of Law. In Autopoietic Law: A New Approach to Law and Society. Ed. Gunther Teubner. New York and Berlin: Walter de Gruyter Publishing.

---- Luhmann, Niklas. 1989. Law as a Social System. Northwestern University Law Review 83: $136-150$

---- Luhmann, Niklas. 1992. Operational Closure and Structural Coupling: The Differentiation of the Legal System. Cardozo Law Review 13: 1419-1441

Maturana, Humberto, and Francisco J. Varela. 1980. Autopoiesis: The Organisation of the Living. In Autopoiesis and Cognition: The Realisation of the Living. Ed. Humberto Maturana, and Francisco J. Varela. Dordrecht: Reidel.

Mingers, John. 1995. Self-Producing Systems: Implications and Applications of Autopoiesis. London: Plenum Press.

Mitleton-Kelly, Eve. 2003. Ten Principles of Complexity and Enabling Infrastructures. In Complex Systems and Evolutionary Perspectives on Organisations: The Application of Complexity Theory to Organisations. Ed. Eve Mitleton-Kelly. London: Pergamon. 
Murray, Jamie. 2006. Nome Law: Deleuze and Guattari on the Emergence of Law. International Journal for the Semiotics of Law 19: 127-151.

---- Murray, Jamie. 2008. Complexity Theory and Socio-Legal Studies, Coda: Liverpool Law. Liverpool Law Review 29: 227-246.

---- Murray, Jamie. 2010. Deleuze and Guattari: Emergent Law. London: Routledge

Phelan, Steven, E. 1999. A Note on the Correspondence Between Complexity and Systems Theory. Systemic Practice and Action Research 12(3): 237-246.

Rescher, Nicholas. 1998. Complexity: A Philosophical Overview. New Brunswick: Transaction Publishers.

Richardson, Kurt, A., Paul Cilliers, and Michael Lissack. 2001. Complexity Science: A 'Gray' Science for the 'Stuff in Between'. Emergence 3(2): 6-18.

Richardson, Kurt, A. 2004a. Systems Theory and Complexity: Part 1. Emergence: Complexity \& Organisation 6(3): 75-79.

---- Richardson, Kurt, A. 2004b. Systems Theory and Complexity: Part 2. Emergence: Complexity \& Organisation 6(4): 77-82.

---- Richardson, Kurt, A. 2005. Systems Theory and Complexity: Part 3. Emergence: Complexity \& Organisation 7(2): 104-114.

Richardson, Kurt, A., and Gerald Midgley. 2007. Systems Theory and Complexity: Part 4, The Evolution of Systems Thinking. Emergence: Complexity and Organisation 9(1\&2): 163180. 
Ruhl, J.B. 1996a. The Fitness of Law: Using Complexity Theory to Describe The Evolution of Law and Society and Its Practical Meaning For Democracy. Vanderbilt Law Review 49: 1407-1490.

---- Ruhl, J.B. 1996b. Complexity Theory as a Paradigm for the Dynamical Law-andSociety System: A Wake-Up Call for Legal Reductionism and the Modern Administrative State. Duke Law Journal 45(March): 849-928.

---- Ruhl, J.B. 1997. Thinking of Environmental Law as a Complex Adaptive System: How to Clean Up the Environment by Making a Mess of Environmental Law. Houston Law Review 34(Winter): 933-1002.

---- Ruhl, J.B. 2008. Law's Complexity: A Primer. Georgia State University Law Review 24(4): 885-991.

Ruhl, J.B., and Harold J. Ruhl Jr. 1997. The Arrow of the Law in Modern Administrative State: Using Complexity Theory To Reveal The Diminishing Returns and Increasing Risks the Burgeoning of Law Poses to Society. University of California Davis Law Review 30(Winter): 405-482.

Ruhl, J.B. and James Salzman. 2002. Regulatory Traffic Jams. Wyoming Law Review 2(2): 253-289

---- Ruhl, J.B. and James Salzman. 2003. Mozart and the Red Queen: The Problem of Regulatory Accretion in the Administrative State. Georgetown Law Journal 91: 757-850.

Sawyer, Robert K. 2005. Social Emergence: Societies as Complex Systems. Cambridge: Cambridge University Press. 
Teubner, Gunther. 1988. Introduction to Autopoietic Law. In Autopoietic Law: A New Approach to Law and Society. Ed. Gunther Teubner. New York and Berlin: Walter de Gruyter Publishing.

Teubner, Gunther. 1993. Law as an Autopoietic System. Oxford: Blackwell.

Thornhill, Chris. 2010. Review: Niklas Luhmann - Law, Justice, Society. Journal of Law and Society 37(2): 380-383.

Urry, John. 2003. Global Complexity. Oxford: Polity Press.

Van Valen, Leigh. 1973. A New Evolutionary Law. Evolutionary Theory 1: 1-30.

Walby, Sylvia. 2007. Complexity Theory, Systems Theory, and Multiple Intersecting Social Inequalities. Philosophy of the Social Sciences 37: 449-470

Waldrop, Mitchell, M. 1994. Complexity: The Emerging Science at the Edge of Order and Chaos. $2^{\text {nd }}$ ed. . London: Penguin Books.

Webb, Julian, 2002. Being a Lawyer/Being a Human Being. Legal Ethics 5(1-2): 130-151

---- Webb, Julian. 2005. Law, Ethics, and Complexity: Complexity Theory and the Normative Reconstruction of Law. Cleveland State Law Review 52 227-242 